\title{
Association of Foods with Hypertension: A Call for Action
}

\author{
Khubaib Samdani, Faiz Rasool, Saad Azhar, Zarish Akhtar, Sarmad Hassan, Tayyab Mumtaz Khan, \\ Sana Mansoor, Madeeha Mumtaz and Shahrukh Khan
}

ABSTRACT

Hypertension (HTN) is a very prevalent health issue around the world. Many factors influence HTN and some of those include diabetes, obesity, gender, age, and diet. Impact of diet on hypertension, is understudied in our region, therefore, this study was set to manifest the effect of diet on HTN prevalence. This cross-sectional study was performed among local Islamabad of population, Pakistan in 3 months from November 2019 to January 2020. 138 people were recruited in study via a developed criterion. Data was collected by self-designed proforma. Data analysis was done by applying IBM SPSS version 25. Descriptive statistics were used for quantitative variables. As data was non-parametric, so we applied nonparametric statistical tests like Mann Whitney test, Kruskal-Wallis test and Spearman correlation analysis were applied to assess, the difference in means of both systolic and diastolic BP between female and male, difference in means of both systolic and diastolic BP among three consumption frequency levels, and association, direction, and strength of between HTN and foods consumption. Present study indicates overall high prevalence of HTN $(39.86 \%)$ among study population. Means of age, systolic and diastolic BP for study population were 43.42 (with SD of \pm 8.30) years, $138.01 \mathrm{mmHg}$ (with SD of \pm 19.37 ), and $89.38 \mathrm{mmHg}$ (with SD of \pm 7.10 ) respectively. Difference in means of both systolic and diastolic between females and males was not significant ( $p=0.093$ and $p=0.078$ respectively) although these were higher among males and gender was not associated with HTN significantly $(p=0.069)$. Strength and direction for association between fast food and HTN was strong and positive, for association between snack food and HTN was strong and positive while for association between fresh fruits and raw vegetables was strong and negative with correlation coefficients $(+0.690$ for diastolic, $+\mathbf{0 . 7 1 0}$ for systolic), $(+\mathbf{0 . 6 5 1}$ for diastolic, $+\mathbf{0 . 6 6 1}$ for systolic), ($\mathbf{0 . 7 1 2}$ for diastolic, $\mathbf{- 0 . 7 1 2}$ for systolic) respectively. In short, present study concludes that HTN was more prevalent among males, fast food, snack foods eaters and fresh fruits and raw vegetables non-eater in contrast to females, fresh fruits and raw vegetables eaters and non-eaters of fast foods and snack foods. Higher consumption of fast foods and snack lead to higher prevalence of HTN and vice versa whereas higher consumption of fresh fruits and raw vegetables bring decline in the incidence of HTN incidence and vice versa. So, we are dependent on awareness among people about the influence of food on HTN and gender specific measures for each gender to reduce HTN incidence.

Keywords: Action, association, call, foods, hypertension.
Submitted : August 29, 2021

Published : October 15, 2021

ISSN: $2593-8339$

DOI: $10.24018 /$ ejmed.2021.3.5.1034

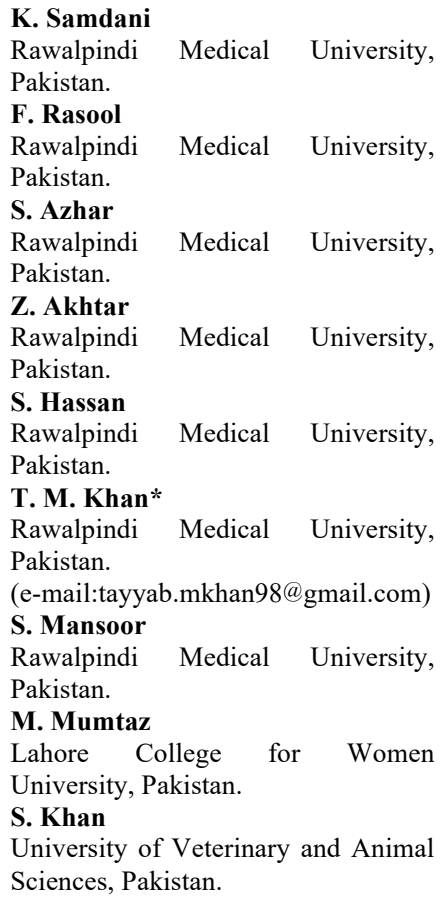

Sciences, Pakistan.

*Corresponding Author

\section{INTRODUCTION}

Hypertension is a very common health problem in whole world. Hypertension pervasiveness is expanding step by step all around the world in second rate class nations as well as in top-of-the-line nations [1], [2]. Hypertension is a very lethal disease as hypertension prompts 7.5 million deaths throughout the planet every year. It is suggested that number of deaths on account of hypertension would be reached to 1.56 billion in 2025 [3], [4]. Alongside any remaining nations of world image of hypertension is indistinguishable in Pakistan. As per one National Health Survey revealed that $18 \%$ of grown-ups and $33 \%$ grown-ups with age more than 40 are influenced by hypertension. It was additionally demonstrated that just around half of all hypertensives were analyzed while just $50 \%$ of those were treated for hypertension. Because of obliviousness of determination and no treatment for all analyzed just $12.8 \%$ hypertensive patients of all were overseen appropriately [5]. A recent study in Pakistan has shown high (45.10\%) prevalence of HTN among Pakistani [6]. These all studies indicates that HTN prevalence has reached to an alarming level.

HTN affects our lives badly all over the world. Despite, the fact that a large portion of individuals with raised circulatory strain (HTN) stay undiscovered in view of no asymptomatic nature of hypertension except for an extent of individuals present with migraines, discombobulation, loss of equilibrium and change in vision [7]. Hypertension prompts passing through numerous deadly illnesses including Stroke, ongoing coronary illness, and renal problem [3], [8]-[10]. Other than previously mentioned diseases hypertension also causes retinal discharge and peripheral vascular illness [3], [11]. So, HTN is not a disease to be ignored in anyway. 
In literature, studies have shown that hypertension is affected by many components like male sexual orientation, age, marriage, top social-class, lower instructive status, tobacco and alcohol utilization, diabetes, sort of exercises, and family background of hypertension [12]-[15]. Alongside these revealed factors in different investigations, diet has been likewise recorded in writing, as one of significant danger factors that leads to hypertension. Although this load of variables essential to control hypertension, however, diet is generally significant as it is known as main driver of many other cardiovascular illnesses like coronary artery disease and GIT and endocrine issues. Fast food leads to HTN and it has been reported in literature. Fast foods may lead to HTN because of their salt content that leads to HTN directly. Whereas higher consumption of green foods like fresh fruit and raw vegetables which are known as healthy foods leads to lower incidence of HTN. So, adjustment in diet would cause control of hypertension as well as acquire decrease other ongoing and threatening diseases of body [16]-[20]. Genuine measures ought to be taken to decrease the intake of unhealthy diet.

Different studies have shown various causes that lead to higher consumption of junk food and lower consumption of fresh fruits and raw vegetables. These include easy availability, easy digestion, tasty and energy enrich nature [21]. Mental diseases like stress and depression are also reported as driving factors for higher consumption of junk foods [22], [23].

Regardless of, many research studies in the world that have been directed to decide the effect of diet on hypertension [16], [17], [19], [20], during literature review, it was noted that information about impact of diet on hypertension in Pakistan, is inadequate. Subsequently, in the light of restricted data about diet and hypertension at our public and especially at nearby level, our study is set with aims to decide relationship of hypertension and diet among territorial and general individuals Islamabad, Pakistan. On the off chance that the aftereffect of current research recommends that hypertension is influenced by diet then by use of appropriate intercessions for awareness about the balanced diet, we would have the option to control raised pulse (HTN) and therefore, frequency of hypertension related demise occurrence would likewise go down.

\section{MATERIAL AND METHODS}

\section{A. Study Design and Study Population}

We utilized comparative cross-sectional study design in this study. This study was done among all inclusive community of Islamabad, Pakistan in very nearly 3 months from November 2019 to January 2020. 138 willing people whose age was over 30 years yet not more than 60 were called up in study in compatibility of set inclusion and exclusion rules. Those individuals whose age was not as per our set models were excluded from study. We applied one selfplanned proforma for data collection. Then, at that point we gave important information in regard to the aims of study. In following stage, we took educated assent from all members for participating in our current research project. Proformas were topped off by meet and important assessments of all selected members.

\section{B. Assessment of Characteristics of Study Population and Blood Pressure}

We applied a self-planned proforma to acquire reasonable and fundamental information about the demographic components like, age and sexual orientation. Subsequent to taking note of socioeconomics subtleties we measured blood pressure (BP), first we utilized Palpatory strategy and afterward for affirmation and diastolic BP evaluation we utilized Auscultatory technique. Just Sphygmomanometer was utilized during palpatory technique while both Sphygmomanometer and stethoscope were utilized during auscultatory strategy. Then, at that point it was noted on selforganized proforma. Individuals with Systolic BP more than $140 \mathrm{mmHg}$ and Diastolic BP more than 90 were considered as hypertensive while underneath these qualities were considered normotensive.

\section{Assessment of Food Intake}

Consumption frequency of three food groups were noted on self-structured proforma among study population in last month and these food groups included Fresh foods like, fruits and raw vegetables, Snack foods items such as potato chips, corn chips and tortilla chips, and fast foods including pizza, burgers, and shawarma. Three consumption frequency levels of each of three included foods were made such as low frequency, moderate frequency, and high frequency. These levels were set by knowing the utilization frequency of each group of food per week during last month. Intake of specific group of food once or less than one a week was viewed low frequency level, 2-3times a week or 4-6times a week was viewed moderate frequency level and once a day and more one times per day was viewed high frequency level of that particular food group. Sweet foods, ready to eat foods, snack foods, and fast foods were labelled poor quality foods, while fruits and vegetables were labelled as good quality healthy foods.

\section{Data Analysis}

IBM SPSS version. 25 was used to perform data analysis. Descriptive statistics were applied to sum up quantitative variables. We applied non-parametric test to analyze data because of its non-parametric nature. Chi square analysis was used, to determine the association between hypertension and gender. Then, to determine the significance of variation in means of both systolic and diastolic blood pressures across gender, Mann-Whitney test was applied. In next step of data analysis, we used Kruskal-Wallis analysis of variance test to assess the significance of differences in means of both type of blood pressures among consumption frequency levels of all included food group. At the end of data analysis, we used rho spearman correlation to evaluate the direction and strength of association hypertension and consumption frequency levels of foods. We set p-value of less than 0.05 statistically significant.

\section{RESUltS}

In our current study from total of 138 people $82(59.42 \%)$ were females and $56(40.58 \%)$ were males. For enrolled study population means of different study variables like age, systolic blood pressure and diastolic blood pressures were 43.42years (with SD of \pm 8.30 ), $138.01 \mathrm{mmHg}$ (with SD of \pm 19.37 ), and $89.38 \mathrm{mmHg}$ (with SD of \pm 7.10 ) respectively. In our study normotensive people were $83(60.14 \%)$ while 
hypertensive people were 55 (39.86\%). Although means of both systolic and diastolic blood pressures were higher among male sex, however, hypertension and gender were not associated significantly $(\mathrm{p}=0.069)$ and it was assessed through chi-square test.

Fig. 1 shows the percentages and number of female and male participants in our study.

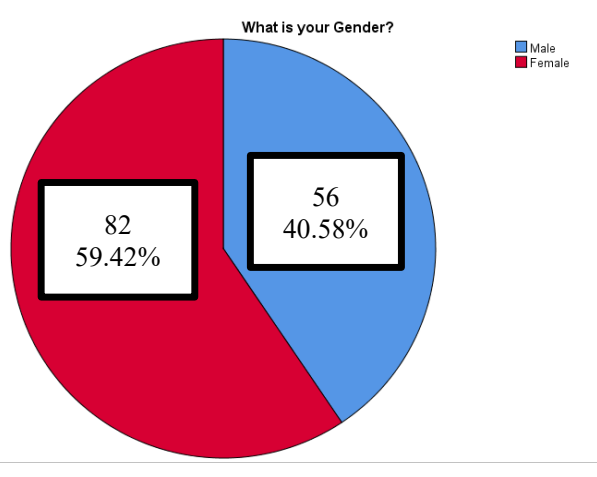

Fig. 1. Gender wise distribution of Study Population.

Table I explains the variation in mean values of systolic and diastolic blood pressures between male and female participants of study. The difference in mean values of both systolic and diastolic blood pressures were not significant statistically as p-values were more than 0.05 and it was assessed by Mann-Whitney test.

Table II indicates disparity in means of systolic blood pressure across three consumption frequency levels of the consumed foods among study population and it also shows that differences of systolic blood pressure mean across three consumption frequency levels of each included three food groups are significant with p-values less than 0.05 for all included food groups. It was evaluated by Kruskal-Wallis test. Likewise, it also explains with the help of Spearman's Correlation and its coefficient that hypertension and included food groups had statistically significant association with pvalues less than 0.05 . The association between fast foods and hypertension, and the association between snack foods and hypertension were positive which means more consumption of these food leads to higher systolic blood pressure while the association between fresh fruits and raw vegetables and blood pressure was negative which means that higher the consumption of these foods, lower would be the systolic blood pressure.

Table III displays difference in mean values of diastolic blood pressure among three consumption frequency levels of foods consumed by study population and it also indicates that variations of diastolic blood pressure mean values across three consumption frequency levels of each included three food groups are significant with $\mathrm{p}$-values less than 0.05 for all included food groups. It was determined by Kruskal-Wallis test. Likewise, it also indicates through Spearman's Correlation and its coefficient that hypertension and included food groups had statistically significant relationship with pvalues less than 0.05 . The correlation between fast foods and hypertension, and the association between snack foods and hypertension were positive which shows more eating of these food causes to higher diastolic blood pressure while the association between fresh fruits and raw vegetables and blood pressure was negative which means that higher the usage of these foods in diet, lower would be the diastolic blood pressure.

TABLE I: DifFERENCE In MEANS OF Both Systolic AND DiAstolic BloOD PRESSURES ACROSS GENDER AND MANN-WhitNEY TEST

\begin{tabular}{ccccc}
\hline \hline \multirow{2}{*}{ Parameter } & \multicolumn{2}{c}{ Gender } & Mann-Whitney test \\
\cline { 3 - 5 } & & Male & Female & p-value \\
\hline \hline Blood & Systolic Mean \pm SD & $143.83 \pm 11.110$ & $138.89 \pm 12.183$ & 0.093 \\
Pressure & Diastolic Mean \pm SD & $88.89 \pm 12.193$ & $87.83 \pm 14.516$ & 0.078 \\
\hline \hline
\end{tabular}

TABLE II: DIFFERENCE IN MEANS OF SYSTOLIC BLOOD PRESSURE AMONG THREE CONSUMPTION FREQUENCY LEVELS OF INCLUDED FOOD GROUPS

\begin{tabular}{|c|c|c|c|c|c|}
\hline \multirow{2}{*}{ Kinds of Food } & \multirow{2}{*}{$\begin{array}{l}\text { Frequency } \\
\text { Levels }\end{array}$} & \multirow{2}{*}{$\begin{array}{c}\begin{array}{c}\text { Systolic-Blood } \\
\text { Pressure }\end{array} \\
\text { Mean } \pm \text { S.D. }\end{array}$} & \multirow{2}{*}{$\begin{array}{c}\begin{array}{c}\text { Kruskal-Wallis } \\
\text { test }\end{array} \\
\text { p-Value }\end{array}$} & \multicolumn{2}{|c|}{ Spearman's Correlation } \\
\hline & & & & $\begin{array}{c}\text { Correlation } \\
\text { coefficient (r) }\end{array}$ & p-Value \\
\hline \multirow{3}{*}{ Fast Food } & High & $145.77 \pm 10.835$ & \multirow{3}{*}{0.0005} & \multirow{4}{*}{0.710} & \multirow{4}{*}{0.0004} \\
\hline & Moderate & $138.19 \pm 11.339$ & & & \\
\hline & Low & $122.89 \pm 10.110$ & & & \\
\hline \multirow{3}{*}{ Snack Food } & High & $144.86 \pm 80.952$ & \multirow{3}{*}{0.0002} & & \\
\hline & Moderate & $135.55 \pm 70.544$ & & \multirow[t]{2}{*}{0.661} & \multirow[t]{2}{*}{0.0005} \\
\hline & Low & $120.45 \pm 90.413$ & & & \\
\hline \multirow{3}{*}{$\begin{array}{c}\text { Fruits and Raw } \\
\text { Vegetables }\end{array}$} & High & $118.83 \pm 12.430$ & \multirow{3}{*}{0.0003} & \multirow{3}{*}{-0.710} & \multirow{3}{*}{0.0001} \\
\hline & Moderate & $126.70 \pm 10.132$ & & & \\
\hline & Low & $138.89 \pm 10.238$ & & & \\
\hline
\end{tabular}

TABLE III: DifFERENCE IN MEANS OF DiASTOLIC BLOOD PRESSURE AMONG THREE CONSUMPTION FREQUENCY LEVELS OF INCLUDED FoOd GROUPS

\begin{tabular}{|c|c|c|c|c|c|}
\hline \multirow{2}{*}{ Kinds of Food } & \multirow{2}{*}{$\begin{array}{l}\text { Frequency } \\
\text { Levels }\end{array}$} & \multirow{2}{*}{$\begin{array}{c}\text { Diastolic-Blood } \\
\text { Pressure } \\
\text { Mean } \pm \text { S. D }\end{array}$} & \multirow{2}{*}{$\begin{array}{c}\text { Kruskal- } \\
\text { Wallis test } \\
\text { p-Value }\end{array}$} & \multicolumn{2}{|c|}{ Spearman's Correlation } \\
\hline & & & & $\begin{array}{c}\text { Correlation } \\
\text { coefficient (r) }\end{array}$ & p-Value \\
\hline \multirow{3}{*}{ Fast Food } & High & $89.18 \pm 9.837$ & \multirow{4}{*}{0.005} & \multirow{4}{*}{0.690} & \multirow{3}{*}{0.008} \\
\hline & Moderate & $88.09 \pm 6.330$ & & & \\
\hline & Low & $83.78 \pm 8.109$ & & & \\
\hline \multirow{3}{*}{ Snack Food } & High & $89.06 \pm 7.952$ & & & \multirow{3}{*}{0.005} \\
\hline & Moderate & $87.55 \pm 7.504$ & \multirow[t]{2}{*}{0.006} & \multirow[t]{2}{*}{0.651} & \\
\hline & Low & $82.88 \pm 9.414$ & & & \\
\hline \multirow{3}{*}{$\begin{array}{c}\text { Fruits and Raw } \\
\text { Vegetables }\end{array}$} & High & $80.11 \pm 9.030$ & \multirow{3}{*}{0.0001} & \multirow{3}{*}{-0.712} & \multirow{3}{*}{0.0003} \\
\hline & Moderate & $81.90 \pm 7.132$ & & & \\
\hline & Low & $85.19 \pm 7.238$ & & & \\
\hline
\end{tabular}




\section{DiscUSSION}

Our study provides very significant information regarding prevalence of HTN among general population of Islamabad, Pakistan and how diet influences the incidence of CAD among study population. In the beginning of data analysis, we noted the value of quantitative variables like means of age of study population which was 43.42 with SD of \pm 8.30 years. Prevalence of HTN was $39.86 \%$. Other studies that were also conducted in Pakistan reported different prevalence of HTN like $45.10 \%$ and $26 \%$ in Lahore and Karachi respectively [6], [24]. After observing quantifiable variables, we noticed that HTN was more common among males as compared to females. This discovery of study was backed by a study that was conducted in Pakistan as well [24]. However, Gender was not associated with HTN significantly with p-value of 0.069 via Chi-square test. Likewise, differences in means of systolic and diastolic pressures were not significant as $p$ values were higher than 0.05 and it was assessed by MannWhitey test. In succeeding stage of data analysis, we recorded that both type of blood pressures was positively but systolic very strongly while diastolic strongly (correlation coefficients $=+0.710$ for systolic and +0.690 for diastolic) related with fast foods which means that with the higher consumption of fast foods, leads to upsurge in the incidence of raised blood pressures of both types and vice versa. Similar results have been displayed in researches in literature [16], [17]. P-values for association between fast food and Systolic BP and Diastolic BP were 0.0004 and 0.008 respectively. Likewise, in next step of data analysis we found again that both kind of blood pressures were positively and strongly (correlation coefficients $=+0.661$ for systolic and +0.651 for diastolic) associated with snack foods which indicates that with the rise in consumption of snack foods, the incidence of raised blood pressures of both types goes up and vice versa. Similar results have been displayed in research articles that were conducted in different parts of world [17], [18]. P-values for correlation between snack food and Systolic BP and Diastolic BP were 0.0005 and 0.005 respectively. Association between fresh fruits and raw vegetables and HTN was negative and very strong (correlation coefficients $=-0.710$ for systolic and -0.712 for diastolic) which shows that these foods are helpful in bringing down the prevalence of HTN. Lower incidence of HTN among fruits and vegetables eaters has been also reported in literature by a studies that were conducted in United States of America and Spain[19], [20]. P-values for association between fresh fruits and raw vegetables and Systolic BP and Diastolic BP were 0.0001 and 0.003 respectively. Relationships between foods and HTN were checked by Chi-square analysis, whereas, direction and strength were assessed through Spearman correlation in cases of all three kinds of food. Different logics have been displayed in literature, that leads to increase consumption of fast food among people in comparison to healthy foods. These reasons include taste, easy digestion, mental disease, and easy availability [21]-[23]. Higher prevalence of HTN among junk food eaters could be due to their higher salt and fat content which make into action various systems of body and consequently leads to raised BP of both types [17], [18].

Albeit present study has impediments as its plan is crosssectional, be that as it may, this investigation actually has very importance as it has featured exceptionally predominant issue. Apparently, the degree we know, present investigation is the lone that affects it among neighborhood populace of
Islamabad, Pakistan. current research suggests that administration should lead meeting for the consciousness of individuals about the job of diet, that what diet means for the strength of overall public, so that we could keep away public from unfortunate eating regimens and eat just sound and healthy diet in a balanced way. More investigates are needed to know causal connection of HTN and diet at territorial and public level.

\section{CONCLUSION}

Our study indicates in general high prevalence of HTN among population of Islamabad. Prevalence of HTN was higher among men, junk food eaters, and fresh fruits and vegetables non-eaters in comparison to women, junk food non-eaters and fresh fruits and vegetables eaters. So, by applying proper measures and awareness sessions regarding proper diet we would be able to reduce prevalence of HTN.

\section{ACKNOWLEDGEMENT}

We (the co-first author, the corresponding author, Dr. Tayyab Mumtaz Khan and all co-authors) thank all respected participants, who participated in this research).

\section{REFERENCES}

[1] P. M. Kearney, M. Whelton, K. Reynolds, P. K. Whelton and J. He, "Worldwide prevalence of hypertension: a systematic review," Journal of Hypertension 1;22(1):11-9, 2004.

[2] C. J. Murray and A. D. Lopez, "Mortality by cause for eight regions of the world: Global Burden of Disease Study," The Lancet 3;349(9061):1269-76, 1997.

[3] S. Mendis, T. Armstrong, D. Bettcher, F. Branca, J. Lauer, C. Mace, V. Poznyak, L. Riley, V. D. Silva and G. Stevens, "Global status report on noncommunicable diseases 2014," World Health Organization 84, 2014

[4] J. S. Tabrizi, H. Sadeghi-Bazargani, M. Farahbakhsh, L. Nikniaz and Z. Nikniaz, "Prevalence and associated factors of prehypertension and hypertension in Iranian population: the Lifestyle Promotion Project (LPP)," Plos One 26;11(10):e0165264, 2016.

[5] Saleem, A. A. Hassali and A. A. Shafie, "Hypertension in Pakistan: time to take some serious action," British Journal of General Practice 1;60(575):449-50, 2010.

[6] J. Akram, H. R. Rehman, F. Muneer, S. Hassan, R. Fatima, T. M. Khan, M. Khizar, S. Tahir, M. Asim, M. Shabbir and S. Asif, "Hypertension and Obesity: A Cross-Sectional Study," European Journal of Medical and Health Sciences 3(4), 90-94, 2021.

[7] K. J. Isselbacher, E. Braunwald, R. G. Petersdorf, J. D. Wilson, J. B. Martin, and A. S. Fauci, "Harrison's principles of internal medicine," McGraw-Hill, 1987.

[8] J. Dubow and M. E. Fink, "Impact of hypertension on stroke," Current Atherosclerosis Reports. 1;13(4):298-305, 2011.

[9] T. Watanabe, T. Kanome, A. Miyazaki and T. Katagiri, "Human urotensin II as a link between hypertension and coronary artery disease," Hypertension Research 29(6):375-87, 2006.

[10] Ku, B. J. Lee, J. Wei and M. R. Weir, "Hypertension in CKD: core curriculum 2019," American Journal of Kidney Diseases 1;74(1):12031, 2019.

[11] M. Bhargava, M. K. Ikram and T. Y. Wong, "How does hypertension affect your eyes?" Journal of Human Hypertension 26(2):71-83, 2012.

[12] S. Singh, R. Shankar and G. P. Singh, "Prevalence and associated risk factors of hypertension: a cross-sectional study in urban Varanasi," International Journal of Hypertension 2017, 2017.

[13] C. El Bcheraoui, Z. A. Memish, M. Tuffaha, F. Daoud, M. Robinson, S. Jaber, S. Mikhitarian, M. Al Saeedi, M. A. AlMazroa, A. H. Mokdad and A. A. Al Rabeeah, "Hypertension and its associated risk factors in the Kingdom of Saudi Arabia, 2013: a national survey," International Journal of Hypertension 6;2014, 2014.

[14] Q. Wei, J. Sun, J. Huang, H. Y. Zhou, Y. M. Ding, Y. C. Tao, S. M He, Y. L. Liu and J. Q. Niu, "Prevalence of hypertension and associated 
risk factors in Dehui City of Jilin Province in China," Journal of Human Hypertension 29(1):64-8, 2015.

[15] S. Bibi, T. M. Khan, W. M. Zafar, M. J. Umer, U. F. Iqbal, M. A. Maqsood, S. Khan, S. Khalil and M. Mumtaz, "Prevalence of Obesity and Impact of Menopause on It among Women of Rural Area of Punjab, Pakistan," European Journal of Medical and Health Sciences 31;3(1):108-11, 2021.

[16] J. Redon, "Hypertension in obesity," Nutrition, Metabolism and Cardiovascular Diseases: NMCD 1;11(5):344-53, 2001

[17] M. Alsabieh, M. Alqahtani, A. Altamimi, A. Albasha, A. Alsulaiman, A. Alkhamshi, S. S. Habib and S. Bashir, "Fast food consumption and its associations with heart rate, blood pressure, cognitive function and quality of life," Pilot Study Heliyon 1;5(5):e01566, 2019.

[18] S. K. Ha, "Dietary salt intake and hypertension," Electrolytes \& Blood Pressure 1;12(1):7-18, 2014.

[19] L. Borgi, I. Muraki, A. Satija, W. C. Willett, E. B. Rimm and J. P. Forman, "Fruit and vegetable consumption and the incidence of hypertension in three prospective cohort studies," Hypertension 67(2):288-93, 2016.

[20] J. M. Nunez-Cordoba, A. Alonso, J. J. Beunza, S. Palma, E. GomezGracia, M. A. Martinez-Gonzalez, "Role of vegetables and fruits in Mediterranean diets to prevent hypertension," European Journal of Clinical Nutrition 63(5):605-12, 2009.

[21] C. Liu, B. Xie, C. P. Chou, C. Koprowski, D. Zhou, P. Palmer, P. Sun, Q. Guo, L. Duan, X. Sun and C. A. Johnson, "Perceived stress, depression and food consumption frequency in the college students of China Seven Cities," Physiology \& Behavior 23;92(4):748-54, 2007.

[22] T. M. Khan, S. Bibi, S. T. Rasool, M. Jamil, S. Khan, H. Shafique, S. U. Jafri, H. Ishfaq, S. Salamat, U. F. Iqbal and H. Amjad, "Impact of Depression on Food Consumption Frequency among Medical Students of Rawalpindi Medical University, Pakistan," European Journal of Medical and Health Sciences 28;2(6), 2020.

[23] T. M. Khan, S. Bibi, T. Shoaib, E. Shoaib, A. Bibi, H. Sajid, S. Khan, A. Sohail, J. Akram, M. Naseer and M. Mumtaz, "Perceived Stress and Food Consumption Frequency among Medical Students of Rawalpindi Medical University, Pakistan," European Journal of Medical and Health Sciences 2(6), 2020.

[24] S. Safdar, A. Omair, U. Faisal and H. Hasan, "Prevalence of hypertension in a low-income settlement of Karachi, Pakistan," Prevalence 2004.

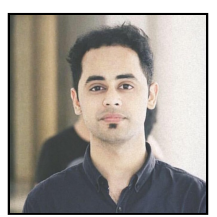

Dr. Tayyab Mumtaz Khan Place and date of birth Lahore, Pakistan 23-3-1996 Educational background: BSC, MBBS. Affiliation: Rawalpindi Medical University, Rawalpindi, Pakistan. 